\title{
Rapid extraction of faecal steroids for measuring reproductive cyclicity and early pregnancy in free-ranging yellow baboons (Papio cynocephalus cynocephalus)
}

\author{
S. K. Wasser*, S. L. Monfort and D. E. Wildt \\ Endocrine Research Laboratory, Conservation and Research Center, National Zoological Park, \\ Smithsonian Institution, Front Royal, VA 22630, USA
}

\begin{abstract}
Summary. A rapid method was developed for extracting and assaying oestradiol and progesterone in faeces $(n=242)$ of female yellow baboons, free-living in Tanzania. Dose response studies generated slopes of $1.02\left(r^{2}=0.99\right)$ for oestradiol and $1.09\left(r^{2}=\right.$ 0.99 ) for progesterone, suggesting that this method accurately measured these steroids in faeces. Parallelism was proved by demonstrating that slopes produced from serially diluted samples were not different from those generated from standard curves (mean $P$ value $=0.53 \pm 0.17$ for oestradiol and $0.44 \pm 0.13$ for progesterone). Faecal progesterone concentrations measured over several cycles in 2 females increased and decreased in correspondence to visual markers of the luteal phase (i.e. the period between sex-skin detumescence and menses), but the presumed preovulatory oestradiol peak was not observed consistently in all cycles. Progesterone profiles during early to midgestation in 3 females confirmed pregnancy by 25 days $(14 \%)$ of gestation. Oestradiol profiles were more variable and were not indicative of pregnancy until 40 days $(22 \%)$ of gestation. Radiolabel-infusion studies revealed that $32 \%$ of progesterone $(n=2)$ but only $11 \%$ of oestradiol $(n=2)$, was cleared through faeces. The latter findings may account for the greater variation observed in temporal oestradiol patterns during the baboon menstrual cycle and pregnancy. Compared with previous techniques, these new methods (i) save considerable time in assaying raw material and (ii) result in high extraction recoveries of faecal steroids ( $\sim 88 \%$ for oestradiol and $91 \%$ for progesterone). This approach may be particularly useful for studying physiological function and endocrine environmental interrelationships in free-living primate species.
\end{abstract}

Key'words: faeces; oestradiol; progesterone; free-ranging; baboon

\section{Introduction}

Noninvasive hormonal measures of reproductive performance (ovulation, luteal function, pregnancy) and physiological stress (adrenocortical activation) can be important in studies in conservation biology, behavioural and physiological ecology, physiological psychology and biomedicine. Measures of steroidal metabolites in excreted urine have proved effective for studying reproductive cyclicity and diagnosing pregnancy in owl monkeys (Bonney et al., 1979), several great ape species (Lasley et al., 1980), cotton-topped tamarin (Brand, 1981), marmoset, lion-tailed macaque (Shideler et al., 1983; Eastman et al., 1984), baboon (Hodges et al., 1986) and rhesus monkey (Monfort et al., 1987). Each of these studies was conducted using captive animals maintained in facilities in which urine could be collected easily. However, this approach has limited

\footnotetext{
*Reprint requests.
} 
value under field conditions because of the practical difficulties in recovering urine from free-living animals.

An alternative is faecal steroid analysis. Because the animal does not have to be disturbed or the excrement recovered immediately after voiding, this noninvasive strategy is potentially applicable to a wide range of species and conditions. Evidence suggests that measurable quantities of gonadal and adrenal steroids are excreted in the faeces of various mammalian species, including man (Adlercreutz \& Jarvenpaa, 1982), orang utan (Shackleton, 1974), rhesus monkey (Shackleton, 1974; Shideler et al., 1989), pigtailed macaque, baboon (Risler et al., 1987; Wasser et al., 1988), slow loris (Perez et al., 1988), cotton-topped tamarin (Ziegler et al., 1988), horse (Choi et al., 1985), cat (Shille et al., 1984), red buffalo, yak, Grevy's zebra and Nubian ibex (Safar-Hermann et al., 1987).

Wasser has published a method for extracting and assaying oestradiol-17 $\beta$ and progesterone in faeces of the pigtailed macaque (Macaca nemestrina; Risler et al., 1987; Wasser et al., 1988) and yellow baboon ( $P$. cynocephalus cynocephalus; Wasser et al., 1988). Although reliable and valid, this method was unsatisfactory because (i) it was labour-intensive, usually requiring $35-40 \mathrm{~h}$ to conduct a single, 20-sample assay; and (ii) the use of petroleum ether for fat extraction also partly extracted progesterone, artificially lowering the actual concentration of this metabolite.

To circumvent these shortcomings, we developed another procedure that reduces extraction time and improves extraction efficiency. The resulting new method uses dichloromethane and eliminates subsequent laborious extraction and chromatography steps in the original method (Risler $e t$ al. 1987; Wasser et al., 1988). This report describes the new method and demonstrates its potential for rapid extraction of excreted steroids in faeces.

\section{Materials and Methods}

Sample collection. Faecal samples were collected from a troop of free-ranging, yellow baboons in Mikumi National Park, Tanzania. This troop has been followed almost daily for the past 17 years as part of a long-term study from 1974 to 1990. Six observers located the study troop by $\sim 06: 30 \mathrm{~h}$ for 5 days/week. Observers positioned themselves around the trees in which the baboons slept, waiting for females to defecate. Additional faecal samples were collected from free-ranging females throughout the day. Each sample, recovered within $5 \mathrm{~min}$ of voiding, was placed in a paper cup and mixed thoroughly to ensure that the steroids were distributed evenly in the faeces. A portion of the well-mixed sample was then placed in weighed, individually labelled $100-\mathrm{m} l$ graduated screw-top vials (containing $0.3 \%$ sodium azide in $35 \mathrm{ml}$ of $100 \%$ ethanol as a preservative (Wasser et al., 1988) until the volume increased by $10 \mathrm{ml}(\sim 10-15 \mathrm{~g}$ of the sample). This provided a ratio of sample:solvent $(0.35 \mathrm{~g} / \mathrm{ml})$ that allowed adequate preservation. Assay development and validation described here involved 242 faecal samples from 8 female baboons.

Visual markers of reproductive condition were recorded daily for all females as they descended from the sleeping trees (Wasser \& Starling, 1988). These included menses (overt blood seeping from the vulva) and tumescence and detumescence of the female's perineal sex-skin (Hendrickx \& Kraemer, 1969). Onset of menses to the last day of tumescence corresponded to a follicular phase, whereas onset of detumescence to the onset of the subsequent menses was defined as a luteal phase (Hendrickx \& Kraemer, 1969). The visual index of pregnancy consisted of pinkening of the female's perineum (Altmann, 1970), which occurs by about Day 50 of gestation (S. K. Wasser, personal observations).

When the observers returned to the base camp, the storage vial containing the faecal sample was weighed and stored in a freezer $\left(-20^{\circ} \mathrm{C}\right)$. Samples were shipped to the USA over a 4-day transit period and reweighed to determine whether leakage had occurred. Samples that leaked were discarded and the remaining samples were refrozen $\left(-20^{\circ} \mathrm{C}\right)$ until dried by rotary evaporation.

Faecal homogenization, centrifugation, fat precipitation and extraction. Preserved faecal samples were evaporated in a Speedvac Rotary Evaporator (Savant Instruments, Inc., Farmingdale, NY, USA) and then reweighed to establish the percentage of sample water. All solid, inert materials (e.g. stones or hard seeds) were removed from the dried sample and weighed and the weights of the inert material subtracted from the wet and dry weights before calculating final sample water content. The resulting dry faecal material $(0.15-0.20 \mathrm{~g})$ was placed in a $50-\mathrm{ml}$, polypropylene, screw-top container, and absolute ethanol $(8 \mathrm{ml})$ and acetone $(2 \mathrm{ml}$; Mallinckrodt, Paris, KY, USA) were added to form a suspension. A total of 6000 c.p.m. $\left[{ }^{3} \mathrm{H}\right]$-oestradiol and 6000 c.p.m. $\left[{ }^{14} \mathrm{C}\right]$-progesterone (NEN, Du Pont Co., Wilmington, DE, USA) was added to monitor extraction recoveries of each hormone. The suspension was homogenized thoroughly using a Sonifier Cell Disruptor (Model W-185C, Bronson Ultrasonics Inc., Melville, NY, USA) at 65 W for $1.5 \mathrm{~min}$. After centrifugation at $2000 \mathrm{~g}$ for $15 \mathrm{~min}$ at room temperature, the ethanol and acetone supernatant was transferred into a $16 \times 125-\mathrm{mm}$ tube. The faecal pellet was combined with an additional $5 \mathrm{ml}$ ethanol, vortexed ( $\mathrm{min}$ ) and recentrifuged and the supernatant was added to the initial ethanol and acetone extractant. This super- 
natant solution was evaporated under nitrogen to $\sim 6 \mathrm{ml} ; 2 \mathrm{ml}$ distilled $\mathrm{H}_{2} \mathrm{O}$ was added to the supernatant, which was then vortexed and dried to $\sim 2 \mathrm{ml}$. After adding $5 \mathrm{ml}$ dichloromethane (Sigma Chemical Co., St Louis, MO, USA) vortexing $(1 \mathrm{~min})$ and allowing to settle $(20 \mathrm{~min})$, the dichloromethane layer was aspirated into $13 \times 100$-mm tubes. The residual fat remaining in the $16 \times 125$ - $\mathrm{mm}$ tubes was then centrifuged at $2000 \mathrm{~g}$ for $5 \mathrm{~min}$ at room temperature and any remaining dichloromethane was aspirated and added to the $13 \times 100-\mathrm{mm}$ tubes. The dichloromethane was evaporated to dryness and redissolved in $1 \mathrm{ml}$ methanol. Extractants were vortexed $(1 \mathrm{~min})$, placed in an ultrasonic glass cleaner (Mettler Electronics, Pasadena, CA, USA) for $30 \mathrm{~s}$ to free particulates adhering to the vessel walls and then vortexed for $15 \mathrm{~s}$. Extractants were counted $(50 \mu \mathrm{l}$ in $10 \mathrm{ml}$ Ready Protein, Beckman Instruments Inc., Fullerton, CA, USA) to determine recoveries using a dual-labelled, quench-curve, compensation programme on a Beckman LS5801 scintillation counter (Beckman Instruments Inc.). Automatic quench compensation accounted for any spillover of ${ }^{3} \mathrm{H}$ into the ${ }^{14} \mathrm{C}$ channel as well as the contrasting situation. Spill-over between ${ }^{3} \mathrm{H}$ and ${ }^{14} \mathrm{C}$ channels (range $100-2000$ d.p.m.) was negligible $(0 \cdot 9-2 \cdot 0 \%)$.

Radioimmunoassay. Hormone concentrations were quantified using procedures described by Risler et al. (1987) and Wasser et al. (1988). Initially, extractants were diluted (oestradiol 1:40; progesterone $1: 200$ ) in $0 \cdot 1 \mathrm{M}$ phosphatebuffered saline (PBS, $\mathrm{pH} 7.0)$ and an aliquant $(300 \mu \mathrm{l}$ oestradiol or $100 \mu \mathrm{l}$ progesterone for nonpregnant animals; $150 \mu \mathrm{l}$ oestradiol or $50 \mu \mathrm{l}$ progesterone for pregnant animals) was adjusted to a final assay volume of $500 \mu \mathrm{l}$ for oestradiol and $400 \mu \mathrm{l}$ for progesterone. The antisera were combined with unknowns and standards $(5-200 \mathrm{pg} / \mathrm{tube}$, Sigma Chemical Co.) and incubated for $2 \mathrm{~h}$ at $4^{\circ} \mathrm{C}$. After the addition of $500 \mu \mathrm{l}$ charcoal-dextran $(0 \cdot 125 \%$ Norit $\mathrm{A}$ Charcoal, $0.0125 \%$ dextran in $0.1 \mathrm{M}$ PBS, $\mathrm{pH} 7.0$ ) and a $15-\mathrm{min}$ incubation at $44^{\circ} \mathrm{C}$, tubes were centrifuged at $1500 \mathrm{~g}$ for $12 \mathrm{~min}$, decanted into scintillation vials, combined with $5.0 \mathrm{ml}$ Ready Protein and counted for $5 \mathrm{~min}$. Hormone concentrations were expressed as ng/g equivalent wet weight faeces (Wasser, et al., 1988).

Dose response study. Each of 8 , randomly selected, dried faecal samples was divided into 4 equal portions of $0.16 \mathrm{~g}$. Unlabelled, standard steroid preparations were added to each portion in increasing doses: $0,8,24$ and $40 \mathrm{ng}$ oestradiol in $40 \mu \mathrm{l}$ and $0,160,480$ and $800 \mathrm{ng}$ progesterone in $800 \mu \mathrm{l}$. Samples were extracted as described above and assayed before and after DEAE Sephadex anion-exchange column chromatography (Risler et al., 1987).

Parallelism. Each of 5 extracted faecal samples was serially diluted 4 times $(1: 2$ to $1: 16)$ and then assayed as described by Risler et al. (1987). Percentage-binding data generated from the standard curve were plotted against their logarithmically transformed doses on the $x$ axis. Data from each of the serially diluted samples were plotted similarly. Slopes and standard errors were obtained for each plot and then tested for parallelism in a series of Student's $t$ tests.

Radiolabelled steroid infusion study. Two unanesthetized, captive, adult female baboons each were injected i.v. with $100 \mu \mathrm{Ci}\left[{ }^{3} \mathrm{H}\right]$-oestradiol and another 2 females were injected with $100 \mu \mathrm{Ci}\left[{ }^{3} \mathrm{H}\right]$-progesterone (Amersham, Arlington Heights, IL, USA). All animals were housed in single animal cages at the Primate Research Unit of the National Institutes of Health, Bethesda, MD, USA. Following isotope injection, syringes were rinsed ( 8 times) with scintillation fluid, residual radioactivity was counted and this residual was subtracted from the preinjection total $(100 \mu \mathrm{Ci})$ to determine the total quantity of infused isotope. After isotope infusion, all urine and faeces were collected for 5 days. Stainless steel pans covered with a removable 6.4-mm mesh screen were placed under each cage to separate faecal material from urine. Urine volume and faecal weights were recorded upon collection and the proportion of isotope excreted was determined. The radioactivity of $1 \mathrm{ml}$ of urine and $0.1 \mathrm{~g}$ of faeces from each, well-mixed sample was measured. Quenched samples were subdivided until their $\mathrm{H}$ numbers were below 140 and their counts were summed. The faecal sample from each animal that contained the highest d.p.m./g was extracted in duplicate for the steroid infused into that animal.

\section{Results}

\section{Extraction recoveries, dose responses and parallelism}

The extraction recovery efficiencies for oestradiol and progesterone $(n=139)$ were $88.3 \pm 0.6 \%$ and $90 \cdot 6 \pm 0 \cdot 6 \%$, respectively. Interassay coefficients of variation for 2 separate internal controls (pooled faecal samples containing high concentrations of oestradiol and progesterone and low concentrations of oestradiol and progesterone, respectively) were both $12 \cdot 0 \%$ for oestradiol and $9 \cdot 5 \%$ for progesterone ( 8 extractions and assays each). Intra-assay coefficients of variation averaged $2 \cdot 1 \%$ for the oestradiol and $2 \cdot 2 \%$ for the progesterone assays.

The oestradiol dose response study generated a curve with a slope of $1.02\left(r^{2}=0.99\right)$ before chromatography and $1.08\left(r^{2}=1.0\right)$ after chromatography (Fig. 1). Mean oestradiol recoveries were $105.90 \pm 0.07 \%$ and $104 \cdot 10 \pm 0.08 \%$, respectively $(n=12$ pairs) over a range of $8-40 \mathrm{ng}$. The dose response study for progesterone produced a curve with a slope of $1.09\left(r^{2}=0.99\right)$ before chromatography and $0.98\left(r^{2}=1.0\right)$ after chromatography (Fig. 2). Mean progesterone recoveries were $109 \cdot 10 \pm 0 \cdot 04 \%$ and $97 \cdot 30 \pm 0.05 \%$, respectively $(n=12$ pairs $)$, over a range of $160-800 \mathrm{ng}$. 


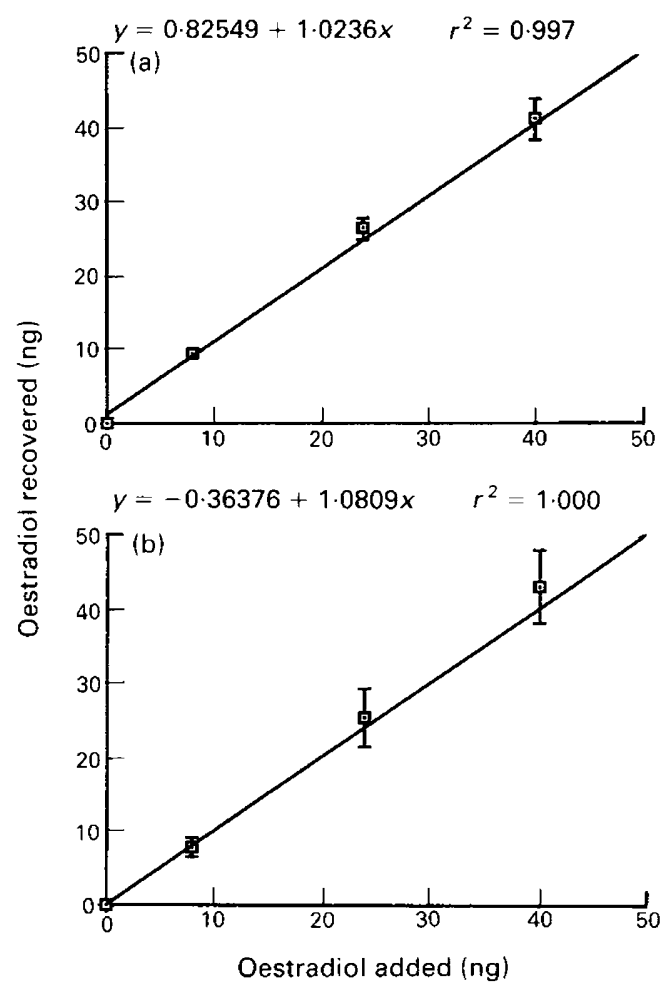

Fig. 1. Dose response curves demonstrating oestradiol recovery (mean \pm s.e.m.) before (a) and after (b) column chromatography, in relation to unlabelled hormone added to the sample from a female baboon before processing ( 4 values/datum point).

The 5 slopes generated from the serially diluted samples in the parallelism study were not different $(P>0.05)$ from the standard curve slope. The average $P$-value was $0.53 \pm 0.17$ for oestradiol and $0.44 \pm 0.13$ for progesterone.

\section{Progesterone and oestradiol concentrations in cycling and pregnant females}

Faecal progesterone concentrations (Fig. 3a) rose during the early luteal phase (as indexed by the onset of detumescence, D) and characteristically declined towards the end of the luteal phase (as indexed by the onset of the menses marker, M). Faecal oestradiol concentrations (Fig. $3 b$ ) tended to peak just before or during the onset of sex-skin detumescence, typically returning to baseline within $24 \mathrm{~h}$. However, unlike progesterone, the oestradiol profile typically contained several inexplicable peaks during the cycle (Fig. 3b).

Faecal progesterone concentrations after conception demonstrated a significant $(P<0.001)$, sustained rise above normal luteal-phase concentrations by Day 25 of gestation to $>400 \mathrm{ng} / \mathrm{g}$ faeces (Fig. 4a). Faecal oestradiol concentrations rose from a baseline concentration of $24 \mathrm{ng} / \mathrm{g}$ to $100-300 \mathrm{ng} / \mathrm{g}$ by $\sim 44$ days of gestation (Fig. $4 \mathrm{~b}$ ), $\sim 19$ days following the rise in progesterone concentrations, but there was considerable variability among females in the temporal characteristics of the oestradiol profile.

\section{Radiolabelled steroid infusion study}

Of the progesterone infused into captive baboons 1 and 2,51 and 57\%, respectively, were recovered in the urine and faeces; 61 and $75 \%$ of the oestradiol infused into baboons 3 and 4 , respectively, 


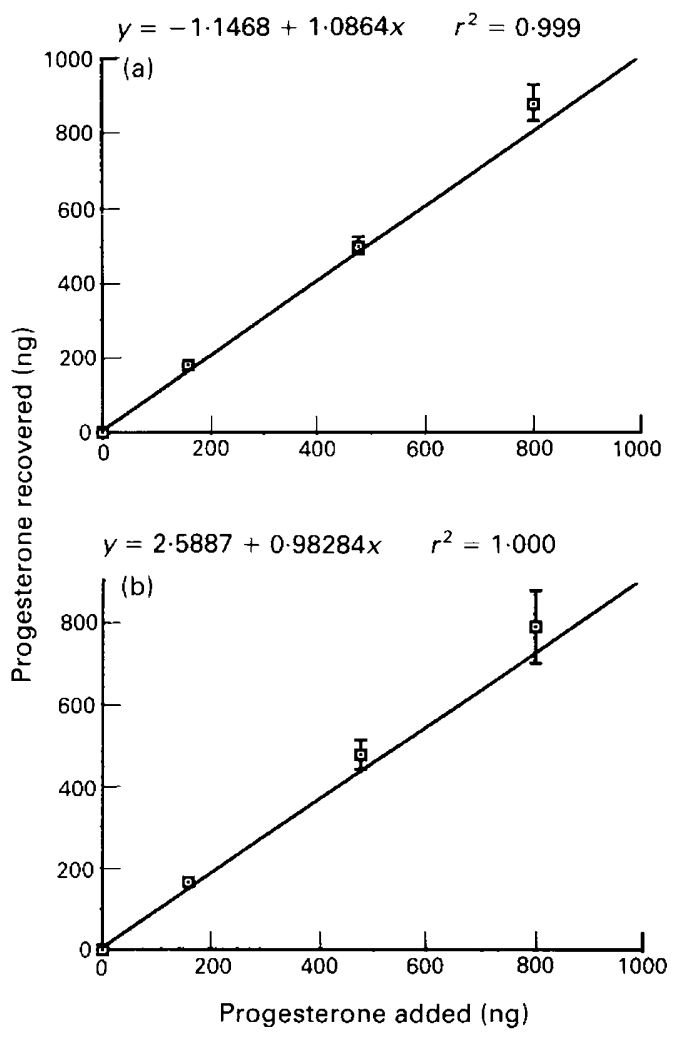

Fig. 2. Dose response curves demonstrating progesterone recovery (mean \pm s.e.m.) before (a) and after (b) column chromatography, in relation to unlabelled hormone added to the sample from a female baboon before processing ( 4 values/datum point).

were recovered in the urine and faeces. Of the progesterone radiolabel recovered, an average of $68 \%$ was recovered in urine and $32 \%$ in faeces; of the oestradiol radiolabel recovered, an average of $89 \%$ was recovered in urine and $11 \%$ in faeces. Extraction efficiency was $77 \%$, based on the total quantity of radiolabelled steroid metabolites recovered in faeces after infusing progesterone and oestradiol.

\section{Discussion}

The ease of collecting faeces should enable investigators to study endocrine profiles in species living under conditions where blood or urine collection is impossible. Large quantities of steroids are excreted in faeces, largely because the principal means of excreting cholesterol - the progenitor of most steroids - is through the gastrointestinal tract via bile (Adlercreutz et al., 1979; Kohlmeier et al., 1986). For this reason, some steroids may be excreted in faeces at concentrations that reflect biological events.

The present study describes a validated rapid method for extracting and measuring steroid hormones in primate faeces. This new procedure resulted in a great saving of time in the laboratory because it eliminated an 18-h fat precipitation, 2 ether extractions, 2 bicarbonate washes and column chromatography, all of which were required in our earlier method (Risler et al., 1987; Wasser et al., 1988). The extraction recovery efficiency was high for both steroids, comparable to that of our earlier methods for oestradiol while increasing by an average of $26 \%$ for progesterone. 
(a) (i)

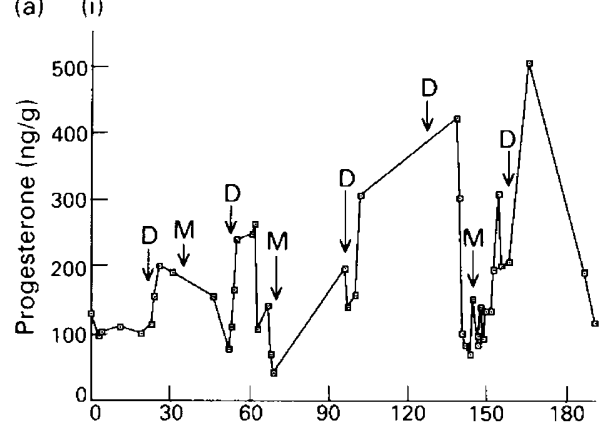

(b)

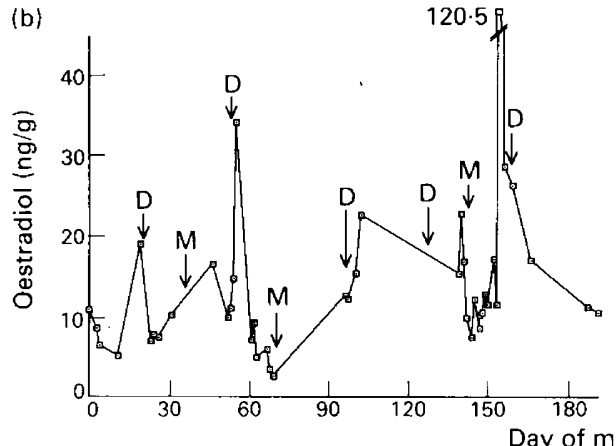

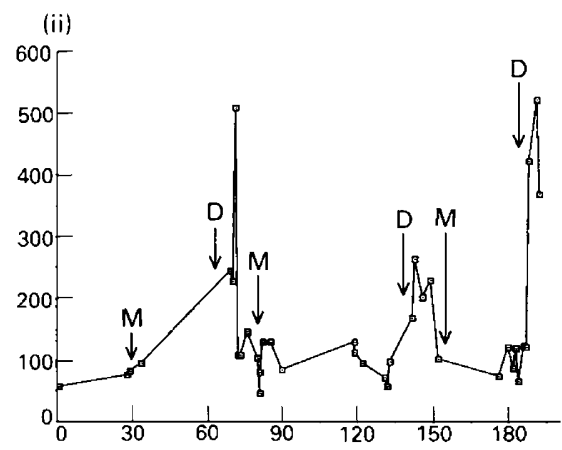

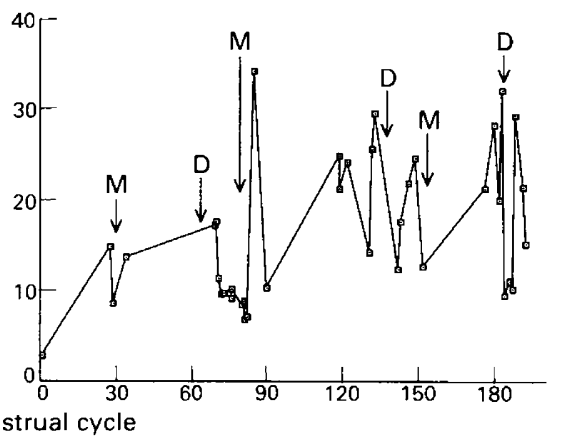

Fig. 3. (a) Faecal progesterone and (b) oestradiol concentrations during consecutive menstrual cycles of 2 free-living baboons (i) and (ii). Time of onset of menses (M) and sex skin detumescence (D) is indicated by arrows.

The high extraction recovery efficiency of this procedure was further substantiated by our ability to recover $77 \%$ of radiolabelled progesterone and oestradiol metabolites contained in faeces after isotope infusion. Dose response studies indicated that the new technique was accurate because virtually $100 \%$ of unlabelled steroid added to the preprocessed sample was recovered with or without chromatographic separation. Parallelism studies also demonstrated that these approaches were effective for measuring naturally occurring steroid content in untreated, extracted samples. The affinity of dichloromethane for most steroids (Wingfield et al., 1975; Pearson-Murphy et al., 1981) suggests that this method may work well for a range of gonadal and adrenal steroids, as well as for other primate and nonprimate species.

Results from faecal hormone analyses of free-ranging baboons indicated that, given adequate sampling, the described techniques were useful for characterizing and retrospectively predicting oestrous cyclicity and the occurrence of ovulation and pregnancy. Cyclicity and ovulation were confirmed by the rise and fall of progesterone excretion during the period from onset of sex-skin detumescence to menses, marking the luteal phase. Using faecal progesterone concentrations, pregnancy was detected reliably by 25 days after conception. Earlier detection may be possible, although this needs to be confirmed by analysing faecal samples collected on a daily basis. The more highly variable and inconsistent fluctuations in faecal oestradiol concentrations indicated that this hormone was less informative than progesterone. The unexplained variation in oestradiol concentrations probably relates to our finding that in this baboon species most oestradiol is excreted in urine rather than faeces. Nevertheless, the dose response and parallelism studies, as well as the high extraction recoveries of oestradiol, suggest that this extraction technique may be effective in other species that excrete greater proportions of faecal oestradiol. We are currently exploring for the presence of other faecal oestrogens that might be more accurate for monitoring baboon reproductive cyclicity. 

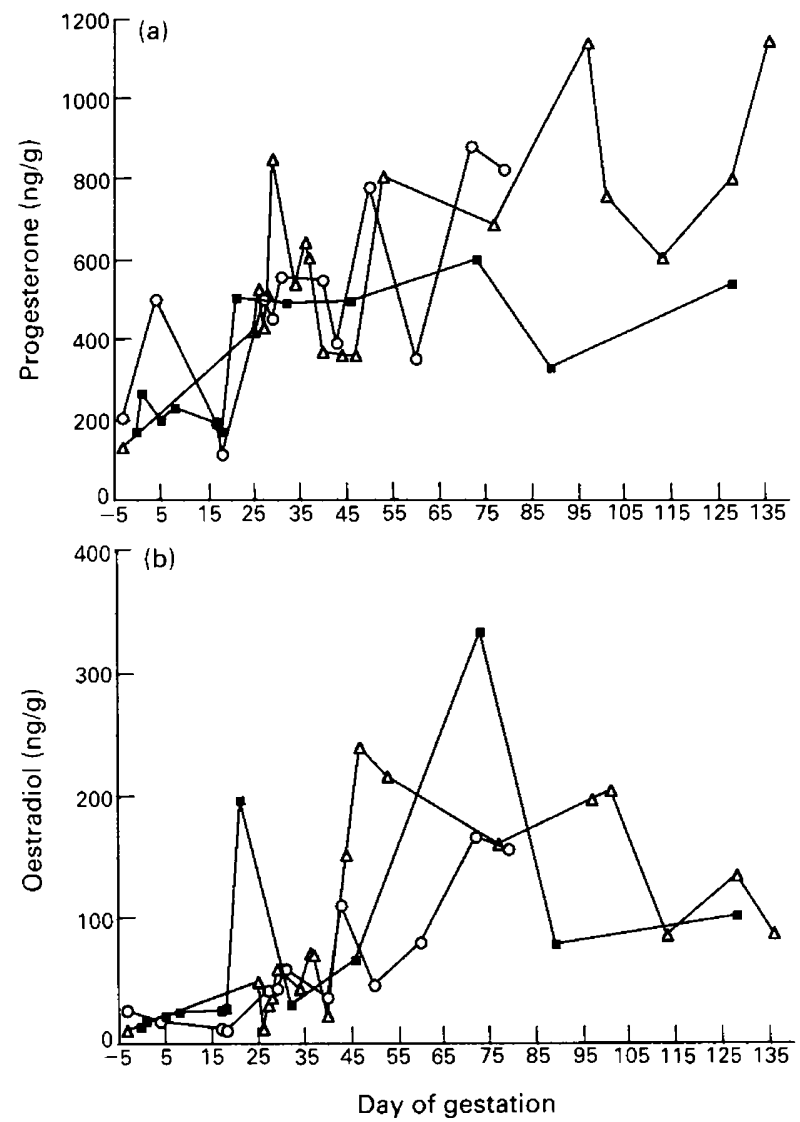

Fig. 4. (a) Faecal progesterone and (b) oestradiol concentrations from 3 female baboons $((\triangle)$ Koho, (O) Sand, ( $\boldsymbol{\square}$ ) Ubavu) from the time of conception. (Day 0, considered equivalent to the first day of detumescence of the conception cycle.)

Faecal steroid analyses offer the potential of addressing many timely, integrative problems in reproduction and conservation biology. There have been few efforts to interrelate behavioural ecology with endocrine activity in free-living mammals, primarily because of the unavailability of the necessary tools. Our results provide evidence that faecal steroid analysis may be important for understanding the complex interrelationships between an animal's physiology and its environment. Faecal steroid analysis techniques could also be used for (i) monitoring reproductive recovery and response of captive bred species following reintroduction into native habitats or of wild species after translocation; (ii) providing unconfounded measures of physiological stress or animal wellbeing in captive propagation studies; and (iii) monitoring the impact of habitat destruction and other forms of human disturbance on free-living species. By reflecting the physiological effects of habitat fragmentations and disruption, faecal steroid analysis could provide a scientifically valid method for continued positive political and legislative action. Our results suggest that such cost-effective strategies may soon be possible.

More work is needed to determine how dietary variability influences steroid excretion rate (Goldin et al., 1981, 1982; Wasser et al., 1988). Until such knowledge is available, within- and between-population comparisons must proceed with caution. Naturally occurring fluctuations in urine excretion rate presented similar problems for investigators relying on urinary hormone measures. For urine, such effects are now controlled by expressing hormone concentrations $/ \mathrm{mg}$ creatinine - a nitrogenous waste product that serves as an index of urine concentration (Shideler $e t$ 
al., 1983). No such compound has been identified for faecal steroid measures and it has not been determined to what extent such an index is necessary. This problem is being studied in our laboratory.

This research was supported by grants to S. K. Wasser from the Leakey Foundation, WennerGren Foundation, the Harry Frank Guggenheim Foundation, the National Geographic Society, the National Institutes of Mental Health RO1 MH45863 and the Smithsonian Institution. The Primate Research Unit of the National Institutes of Health provided captive animals, per diem and full veterinary support. Support was also contributed by grants to D. E. Wildt from the Friends of the National Zoo and the Scholarly Studies Program of the Smithsonian Institution. We thank L. Stratton, S. Kleindorfer, C. Kidungho, A. Njalale and W. Marwa for sample collections in the field and J. Lucas, B. Ferguson and S. Lipton for collection from captive animals; the Tanzania Commission for Science and Technology, the Serengeti Wildlife Research Institute and Tanzania National Parks for permission to conduct this research in Mikumi National Park, Tanzania; and N. Arthur, J. Brown, B. Lasley, L. Risler and J. Southers provided technical assistance and advice.

\section{References}

Altmann, S.A. (1970) The pregnancy sign in savannah baboons. Lab. Anim. Med. 6, 7-10.

Adlercreutz, H. \& Jarvenpaa, P. (1982) Assay of estrogens in human feces. J. Ster. Biochem. 17, 639-645.

Adlercreutz, H., Martin, F., Jarvenpaa, P. \& Fotsis, T. (1979) Steroid absorption and enterohepatic recycling. Contraception 20, 210-223.

Bonney, R.C., Wood, D.J. \& Kleiman, D.G. (1979) Cyclic changes in the circulating and urinary levels of ovarian steroids in the adult female owl monkey (Aotus trivirgatus). J. Reprod. Fert. 56, 271-280.

Brand, H.M. (1981) Urinary oestrogen excretion in the female cotton-topped tamarin (Saguinus oedipus oedipus). J. Reprod. Fert. 62, 467-473.

Choi, H.S., Mostl, E. \& Bamberg, E. (1985) Confirmation of pregnancy in mares by enzyme immunoassay of oestrogens in faeces. Zentbl. Vet. Reih. A. 32, 760763

Eastman, S.A.K., Makawiti, D.W., Collins, W.P. \& Hodges, J.K. (1984) Pattern of excretion of urinary steroid metabolites during the ovarian cycle and pregnancy in the marmoset monkey. J. Endocr. 102, $19-26$.

Goldin, B.R., Adlercreutz, H., Dwyer, J.T., Swenson, L., Warram, J.H. \& Gorbach, S.L. (1981) Effect of diet on excretion of estrogen in pre- and post-menopausal women. Cancer Res. 41, 3771-3773.

Goldin, B.R., Adlercreutz, H., Gorbach, S.L., Warram, J.H., Dwyer, J.T., Swenson, L. \& Woods, M.N. (1982) Estrogen excretion patterns and plasma levels in vegetarian and omnivorous women. New Eng. J. Med. 307, 1542-1547.

Hendrickx, A.G. \& Kraemer, D.C. (1969) Observations of the menstrual cycle, optimal mating time and preimplantation embryos of the baboon, Papio anubis and Papio cynocephalus. J. Reprod. Fert., Suppl. 6, 119-128.

Hodges, J.K., Tarara, R., Hearn, J.P. \& Else, J.G. (1986) The detection of ovulation and early pregnancy in the baboon by direct measurement of conjugated steroids in urine. Am. J. Primatol. 10, 329-338.
Kohlmeier, M., Hill, T., Remer, P. \& Schlierf, G. (1986) Influence of bezafibrate on plasma lipoproteins, biliary lipids and fecal sterols in healthy men. Atherosclerosis 60, 29-35.

Lasley, B.L., Hodges, J.K. \& Czekala, N.M. (1980) Monitoring the reproductive cycle of great apes and other primate species by determination of estrogen and $\mathrm{LH}$ in small volumes of urine. J. Reprod. Fert. 28, $121-129$.

Monfort, S.L., Hess, D.L., Shideler, S.E., Samuels, S.J., Hendrickx, E.G. \& Lasley, B.L. (1987) Comparison of serum estradiol to urinary estrone conjugates in the rhesus macaque (Macaca mulatta). Biol. Reprod. 37, 832-837.

Pearson Murphy, B.E., Manor Okouneff, L., Klein, G.P. \& Ngo, S.C. (1981) Lack of specificity of cortisol determinations in human urine. J. clin. Endocrinol. Metab. 53, 91-99.

Perez, L.E., Czekala, N.M. \& Weisenseel, K.A. (1988) Excretion of radiolabeled estradiol metabolites in the slow loris (Nycticebuc coucang). Am. J. Primatol. 16, 321-330.

Risler, L., Wasser, S.K. \& Sackett, G.P. (1987) Measurement of excreted steroids in Macaca nemestrina. Am. J. Primatol. 12, 91-100.

Safar-Hermann, N., Ismail, M.N., Choi, H.S., Mostl, E. \& Bamberg, E. (1987) Pregnancy diagnosis in zoo animals by estrogen determination in feces. Zoo Biol. 6, 189-193.

Shackleton, C.H.L. (1974) Steroid excretion in the neonatal period: A comparative study of the excretion of steroids by human, ape, and rhesus monkey infants. J. Ster. Biochem. 5, 113-118.

Shideler, S.E., Czekala, N.M., Benirschke, K. \& Lasley, B.L. (1983) Monitoring ovulation and implantation in the lion-tailed macaque (Macaca silenus) through urinary estrone conjugate evaluations. Biol. Reprod. 29, 905-911.

Shideler, S., Haggerty, M.A. \& Lasley, B.L. (1989) The excretory time course and metabolic fate of ovarian and adrenal steroids in Macaca mulatta. Biol. Reprod., Suppl. 1, 40, 105 (abstr.). 
Shille, V.M., Wing, A.E., Lasley, B.L. \& Banks, J.A. (1984) Excretion of radiolabeled estradiol in the cat (Felis catus, L.): a preliminary report. Zoo Biol. 3, 201-209.

Wasser, S.K., Risler, L. \& Steiner, R.A. (1988) Excreted steroids in primate feces over the menstrual cycle and pregnancy. Biol. Reprod. 39, 862-872.

Wasser, S.K. \& Starling, A.K. (1988) Proximate and ultimate causes of reproductive suppression among female yellow baboons at Mikumi National Park, Tanzania. Am. J. Primatol. 16, 97-121.
Wingfield, J.C. \& Farner, D.S. (1975) The determination of five steroids in avian plasma by radioimmunoassay and competitive protein-binding. Steroids 26, 311-327.

Ziegler, T.E., Sholl, S.A., Scheffler, G. Haggerty, M.A. \& Lastey, B.L. (1988) Excretion of estrone, estradiol and progesterone in the urine and feces of the female cotton-top tamarin (Saguinus oedipus oedipus). Am. J. Primatol. 17, 185-195.

Received 28 August 1990 